\title{
Modeling and Simulation of Consumer Preference Decision for Commercial Complex Location Based on System Dynamics
}

\author{
Bin Guo $\mathbb{D})^{1,2}$ Bing Zhang $\mathbb{D}^{1}{ }^{1}$ and Yang Li $\mathbb{D}^{2}$ \\ ${ }^{1}$ School of Management, Xi'an University of Architecture and Technology, Xi'an, China \\ ${ }^{2}$ School of Public Administration, Xi'an University of Architecture and Technology, Xi'an, China \\ Correspondence should be addressed to Yang Li; liyang@live.xauat.edu.cn
}

Received 28 October 2021; Accepted 14 December 2021; Published 10 January 2022

Academic Editor: Punit Gupta

Copyright $(2022$ Bin Guo et al. This is an open access article distributed under the Creative Commons Attribution License, which permits unrestricted use, distribution, and reproduction in any medium, provided the original work is properly cited.

\begin{abstract}
The influencing factors of consumer shopping behavior play a key role in the later performance of commercial real estate enterprises. On the basis of analyzing the influence factors of customer patronage and the influence factors of commercial complex site selection decision and their relationship, a causal relationship graph and a system dynamic model are established, which can describe the influence of customer preference on commercial complex site selection decision. And introducing customer subjective factors optimize the original pure objective factors site selection decision model. The model is implemented by using the system dynamics modeling tool Vensim. At the same time, the model is verified by using the data of the first-hand investigation. The results show that the calculated data of the model is in good agreement with the actual data. The results show that the system dynamics method can effectively simulate the influence of various factors on the decision-making of the commercial complex. As the forecast of the model, the key indexes of the decision-making of the city commercial complex are discussed, and the measures to be taken are put forward, which can provide reference for the decision-making of the location.
\end{abstract}

\section{Introduction}

With the development of social economy and the increasing income of urban residents, consumer's consumption demand is also gradually becoming rich and diversified. More and more preference is given to the large commercial complex, which integrates commerce, hotel, culture and entertainment, catering, and office. This demand strongly promotes the rapid development of commercial complex. Site selection has great influence on the business operation and development in the later stage of the commercial complex. The decision-making of commercial complex is a complicated process, and it is immutable and irreversible. Whether the decision-making of location can be made scientifically is the precondition and necessary condition for the success of the business. But, in practice, most of the objective factors, such as regional economic level, population distribution, business circle, and traffic, are taken as the decision-making factors of location. But factors of consumer subjective that influence the location of commercial complex are rarely considered. Therefore, this paper from the perspective of consumer preference decision is of more practical significance.

The study of site selection for commercial complex has been strongly promoted. In 1929, Hotelling published a study on the location of two competing ice cream vendors on a straight line. The first study of competitive location is carried out [1]. The Hotelling model is the basic research model of competitive location. The paper studies the location of two competitive stores in a line and brings together the economic, geographical, and game theory. On this basis, many scholars put forward the competition location model from different angles. At present, the research on competitive site selection domestically and abroad has been mature, which is divided into three main types: competitive site selection, static competition site selection, and dynamic competition site selection, and the mature competition site selection theory and related model are formed [2-5].

In practice, after the commercial complex site selection, construction and start of business, the location, 
transportation convenience, the level of regional economic development, natural resource conditions and operational level, and other factors will have a major impact on the consumer's willingness. Besides the level of operation, these major factors, all in the site selection decision-making phase have been determined, and it is difficult to change again. Competitive location of the largest market share must be based on commercial complexes that attract the largest range of consumers. Most of the research methods of domestic and foreign scholars on the site selection of commercial complexes are based on objective factors, such as location, population distribution, business circle, and traffic conditions, while few subjective studies are conducted on consumers' intention of patronage and behavioral differences. The fuzzy analytic hierarchy process, analytic hierarchy process, comprehensive evaluation model, cluster analysis, and SEM analysis are adopted to minimize the risk of site selection decision by determining the index evaluation system of commercial complex site selection. Some scholars use GIS and consider using spatial analysis methods to process spatial data and find the optimal location for shopping malls. The consumer patronage intentions of this research are introduced into the study of the commercial complex's site selection. Through the analysis and identification of the main factors influencing the consumer patronage intentions to guide commercial complex site selection, site selection in decision-making phase will increase the consumer patronage intentions to maximize market share factors, which were fully considered. Location decision is regarded as a complex system composed of many elements.

Therefore, based on the analysis of the influence factors and their relationship between the decision-making system and the decision-making system of the commercial complex, this paper considers the decision-making system as a whole according to the rational behavior theory and the planning behavior theory and establishes a system dynamic model, which can describe the influence of the decision-making of the commercial complex, and verifies the validity of the model through simulation.

\section{Analysis of Location Decision System for Patronage and Commercial Complex}

2.1. Analysis of Influencing Factors of Patronage. The primary premise of studying the consumers' patronage is to identify the key factors that affect the patronage, and it is necessary to identify the key factors that influence the consumers' patronage.

2.1.1. Regional Stereotypes. Stereotypes are the cognition of a certain thing formed in people's activities and interactions. The later people's understanding is based on the foundation of the former and is vulnerable to subjective restrictions, making the later awareness of the constraints [6]. Regional stereotype is a cognitive structure that covers the individual's recognition and expectation in a certain region [7]. Because of the difference of living environment and culture, there are differences in the perception of the individual in different regions for a long time. The perception of the individual has "specificity" and "regionality," which are embodied in the special geographic imprint of the region, the values, and the sense of belonging of the individual.

2.1.2. Consumer Behavior Patterns. Consumers gradually form a specific lifestyle under the influence of their internal and external factors. This unique way of life can create a demand and desire that match consumers. And these needs and desires need to be met by specific consumer behaviors. Some consumers turn to a commercial complex to buy a product or service, which is often called a utilitarian consumer. Other consumers who favor a commercial complex are not just shopping or consuming, and they view the commercial complex as a form of leisure or entertainment [8].

2.1.3. Traffic Convenience. The shopping trips of consumers are always aimed at the lowest cost, and the time cost spent in traffic is one of the main factors that affect consumers' preference for commercial complexes, and due to the homogeneity of business complexes, consumers rarely "go closer" for shopping or consumption [9].

2.1.4. Regional Natural Conditions. A good natural environment will have an impact on consumer demand, consumption structure, consumption level, and mode of consumption [10]. Abundant natural, human landscape resources and clean surrounding environment will create a sense of pleasure to boost consumption, and if a commercial complex is built around parks or tourist attractions, it will increase consumers' willingness to go [11].

2.1.5. Regional Economic Conditions. If the industrial structure of the urban areas is reasonable, the foundation is good, the population density is large, the economic development is better, the urban public supporting resources will be better, and the consumption level of surrounding residents will be correspondingly higher. In those areas with backward industries and no other advantages such as transportation, the economic development is relatively poor, and the consumption level of the surrounding residents is relatively low [12]. Regions with good economic development are more attractive to groups with high academic level, high income, and high consumption.

2.1.6. Operational Level. The operational level of the commercial complex usually includes the variety of goods, shopping environment, service level, and so on. And even the light, color, and smell of the complex will influence the consumer's willingness. If it can have obvious advantages in the commercial form, service level, internal environment, and price compared with other commercial complexes in the same city later, or it can provide personalized services which are not available in other commercial complexes [13], it will attract more consumers. 
2.2. Analysis of the Influence Factors of Business Complex Decision. The urban commercial circle represents the level of economic development of a city to a certain extent. The development of commercial circle can attract more commercial complex projects, which further promote the development of urban commercial circle and are interdependent and mutually promoted. Based on the theoretical analysis of regional growth pole, the factors affecting the decision-making of commercial complex site include economy, politics, culture, location, environment, and other five categories, covering the urban development, policy, consumer culture, location, transportation, natural environment, and other aspects of the content. A comprehensive table of factors affecting the decision-making of commercial complex site is presented.

Twelve experts with senior experience were selected from senior practitioners in institutions of higher learning and industries. Based on the theoretical analysis of regional growth pole theory and the five-force theory, the paper puts forward a table of factors influencing the business complex site selection decision and asks experts to judge the influence of the selected index factors on the business complex site selection decision on a scale of one to five according to their experience. After the first round of the survey was completed, the findings were recycled, inconsistent information was fed back to the experts, and then, the second round of the survey was launched. On this basis, the weight of each index is analyzed by using the analytic hierarchy process, and finally the influencing factors and the weight of each index are determined, as shown in Table 1.

\section{Patronage Affects the Decision-Making of Commercial Complex}

3.1. System Dynamics Model. System dynamics is based on system theory, supplemented with feedback theory and information theory to study information feedback science. The theory was founded in 1956 by Professor Jay W. Forrester of MIT in the United States, and the core of the theory is the system dialectical view, from the point of view of the whole, connection, movement, and development, to study the problem and emphasize the use of qualitative and quantitative methods to analyze the system $[14,15]$.

The system dynamics has the following characteristics, which makes it better to study the consumer's preference for decision-making of commercial complex location decision. (1) The research of system dynamics is mainly aimed at the social and economic system, which has a good pertinence to the research of this paper. (2) The system dynamics adopts the combination of quantitative analysis and qualitative analysis, which breaks the deficiency of the traditional research, and can more truly simulate the characteristics of the business complex preferential system. (3) It can clearly reflect the various internal feedback, including implicit and intuitive. The decision-making factors of commercial complex location are complex, and the system dynamics can be used to express these circuits, and the relationship between various factors and internal and external systems can be clarified.
3.2. Causal Relationship of Site Selection for Commercial Complex. Based on the research results of the previous paper, the content boundary of the system includes six aspects: regional stereotypes, consumer behavior patterns, traffic facilitation, natural environment, regional economic development, and operation level, and six subsystems corresponding to them are formed.

Regional stereotypes have an impact on consumers' regional identity, values, and sense of community ownership. The extent to which consumers have a geographical impression of the region where the business complex is located is directly proportional to their willingness to benefit. Consumers are affected by their own values such as preferences and believe that the sense of group belonging gained by the commercial complex consumption in different regions will be different. The stronger the sense of group belonging is, the higher the chance of generating the willingness to favor [16-18] will be.

Consumer behavior patterns can be influenced by a variety of factors, among which consumers have strong personal attributes such as gender, age, and income [19]. In addition, the personalized differences of consumer behavior patterns are mainly affected by the factors such as the income level, occupation, educational background, age, family structure, and external factors, such as social class and social culture [20]. The chances of a consumer getting a high income are positively correlated with education, and the higher the income, the stronger the purchasing power. And the growth of consumer age will change the structure of the family. External factors mainly refer to the group and class of consumers and the consumption environment [21].

In this paper, the dynamic analysis of traffic factors is performed according to four aspects, namely, time, reliability, selection, and comfort. The preference for business complexes decreases with increasing travel time, reflecting consumers' preference for business complexes, which is less time-consuming in traffic. The distance between the commercial complex and the consumer, the geographical situation around the commercial complex, and the convenience of transportation will affect the time spent by the consumer [22]. Moreover, the safety of traffic and the selectivity of transportation also matter to the consumers when they produce preferential behavior, showing positive correlation.

The natural environmental factors and environmental quality of the region will have a great influence on the location of the commercial complex [23]. Consumers are more inclined to favor those areas with relatively flat terrain, unique natural landscape, historical and cultural relics, and other resources, and factors such as regional ecological indicators, air quality, and road cleanliness will also affect consumers' preference. Consumers usually have multiple objectives when traveling, and consumers will give priority to those areas with relatively complete public support.

The level of urbanization is a measure of the level of development of a regional economy that can attract more potential consumers. At the same time, the improvement of regional infrastructure with high level of economic development can attract more talents, and there is a clear positive relationship between the level of economic development and 
TABLE 1: Factors affecting the site selection of commercial complexes.

\begin{tabular}{|c|c|c|c|}
\hline Target layer & Criterion layer & Secondary indicator & Weight \\
\hline \multirow{15}{*}{$\begin{array}{l}\text { A commercial complex } \\
\text { site selection decision }\end{array}$} & \multirow{3}{*}{ B1 politics } & U11 government policy & 0.14 \\
\hline & & U12 medium- and long-term urban development plan & 0.07 \\
\hline & & U21 level of economic development & 0.07 \\
\hline & \multirow{4}{*}{ B2 economy } & U22 population & 0.05 \\
\hline & & U23 disposable income per capital & 0.04 \\
\hline & & $\mathrm{U} 24$ industrial structure & 0.02 \\
\hline & & U25 development potential & 0.03 \\
\hline & \multirow{2}{*}{ B3 culture } & U31 consumer culture & 0.11 \\
\hline & & U41 traffic facilitation & 0.11 \\
\hline & \multirow{3}{*}{ B4 location } & U42 infrastructure facilities & 0.08 \\
\hline & & U43 business district & 0.15 \\
\hline & & U44 level of competition & 0.05 \\
\hline & \multirow{3}{*}{ B5 others } & U51 surrounding natural resources and environment & 0.04 \\
\hline & & U52 topography & 0.02 \\
\hline & & U53 geological conditions & 0.02 \\
\hline
\end{tabular}

the location of commercial complex [24]. Regions with high economic development levels can attract more investors to build a commercial complex, thus forming a "business circle" within a certain geographic scope, increasing the attractiveness of the whole region to consumers.

The business type, service level, shopping environment, and price level of the commercial complex are also the main factors that influence the customer's preference. The trade form is the quantity of the commodity which can be provided by the commercial comprehensive carrier for the consumer to choose, and its abundance is directly related to the consumer's willingness to favor. Consumers prefer to consume in the commercial complex where the shop assistants can provide high quality service, besides women's private parking spaces, special room for mother and infant, women's exclusive floors, and so on. Consumers prefer commercial complexes that offer good shopping environments such as indoor air flow, pleasant smell, clear signs, light and soft lighting, and relaxing background music. There is a clear positive correlation between the business complexes and the consumer, which means the more they are focused on hot topics and create a good internal and external atmosphere, the more attractive it is to consumers [25].

Through the previously mentioned analysis, the causality diagram of the influence of various factors on the site selection of commercial complex can be constructed (see Figure 1).

3.3. System Dynamics Flowchart. Based on the previously mentioned analysis, a stock map of the location of the commercial complex can be drawn as shown in Figure 2.

\section{Model Simulation}

As Xi'an is a central city in China, it has a good economic and population foundation and is less affected by the network of neighboring cities than the eastern coastal cities, so it has the foundation for the independent analysis of the impact of commercial site selection in large cities in this study. This paper uses the system dynamics modeling software Vensim to implement the model, based on the indicators and data Xi'an City Statistics Bureau published, as well as the business complex A project data, to verify the model. Since the business complex A of this study started to operate in December 2008, the simulation time of this study is set to 2008-2018, and the simulation step is one year, with a total of 10 years.

4.1. Simulation Result Analysis. In order to quantify the preference of consumers, consumers are divided into groups with preference and groups without preference, and the growth rate of preference is used as the rate variable to generate the preference of the population as the stock. The growth rate of preference is mainly affected by regional stereotypes, consumer behavior patterns, traffic convenience, natural resources, regional economic development, and operation level. Through system dynamics simulation, the final preference of simulation results is obtained (Figure 3).

As can be seen from the simulation results, the final willingness to patronize in the simulation period presents three stages of change: steady phase, slow growth phase, and rapid growth phase. In the early development of business complex, the infrastructure and service level are at the primary level, and the customer groups coming to the complex are less, so the development is relatively stable. With the improvement of transportation and other infrastructures, the continuous improvement of the service level, and the impact of word of mouth, the number of consumers who will purchase in the commercial complex gradually increase. The later business complex will form its own fixed customer group, and the fixed customer will lead to the surrounding potential consumers, therefore showing a trend of rapid growth.

Compared with the ultimate preference, the total income of the commercial complex has a more obvious trend of change. For example, in Figure 4, the early commercial complex needs to increase the publicity, promotion, and early-stage investment. The customer experience and the level of employee service are low, so the total income is low 


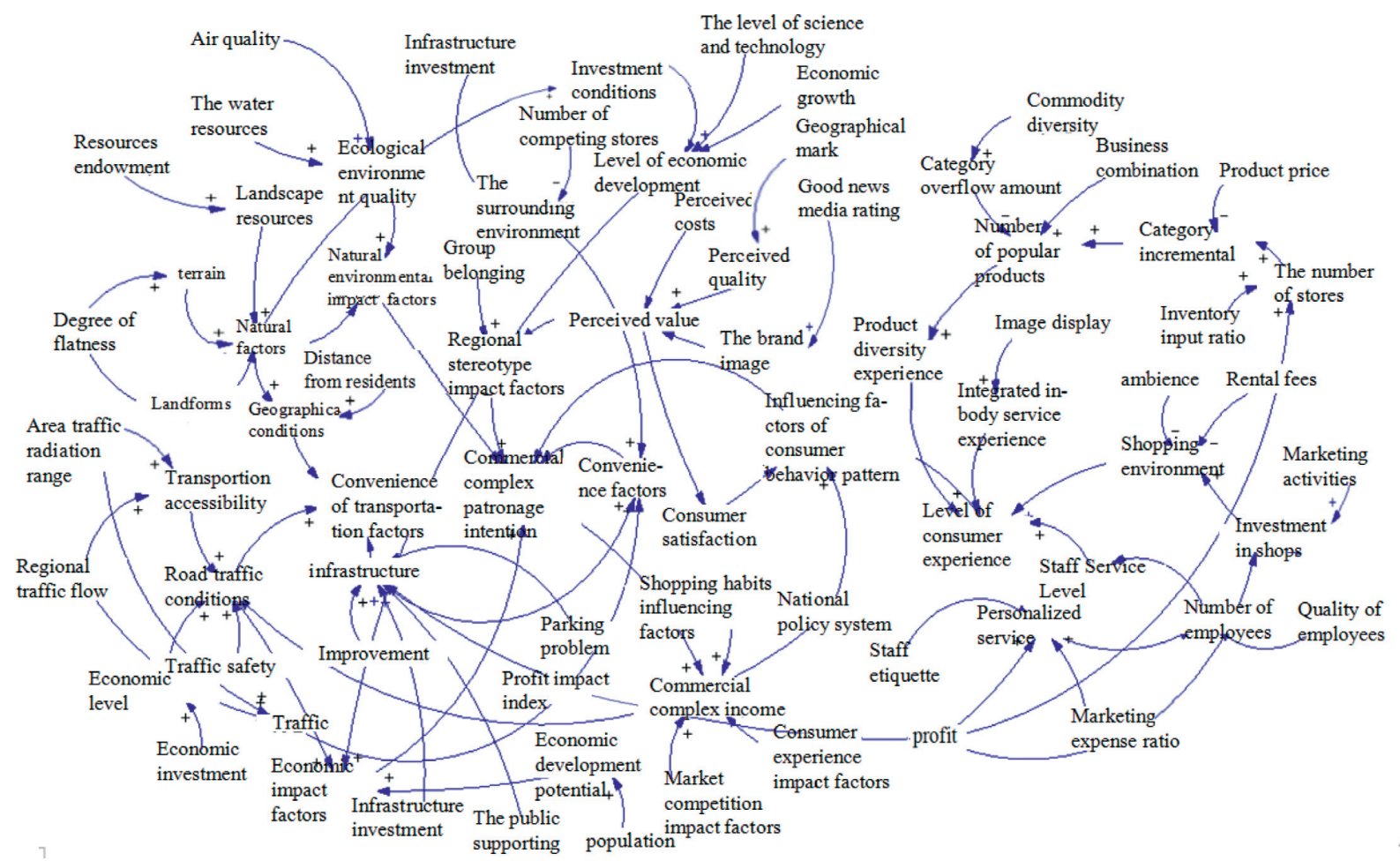

FIgURE 1: Causal relationship diagram for the location of commercial complex site selection.

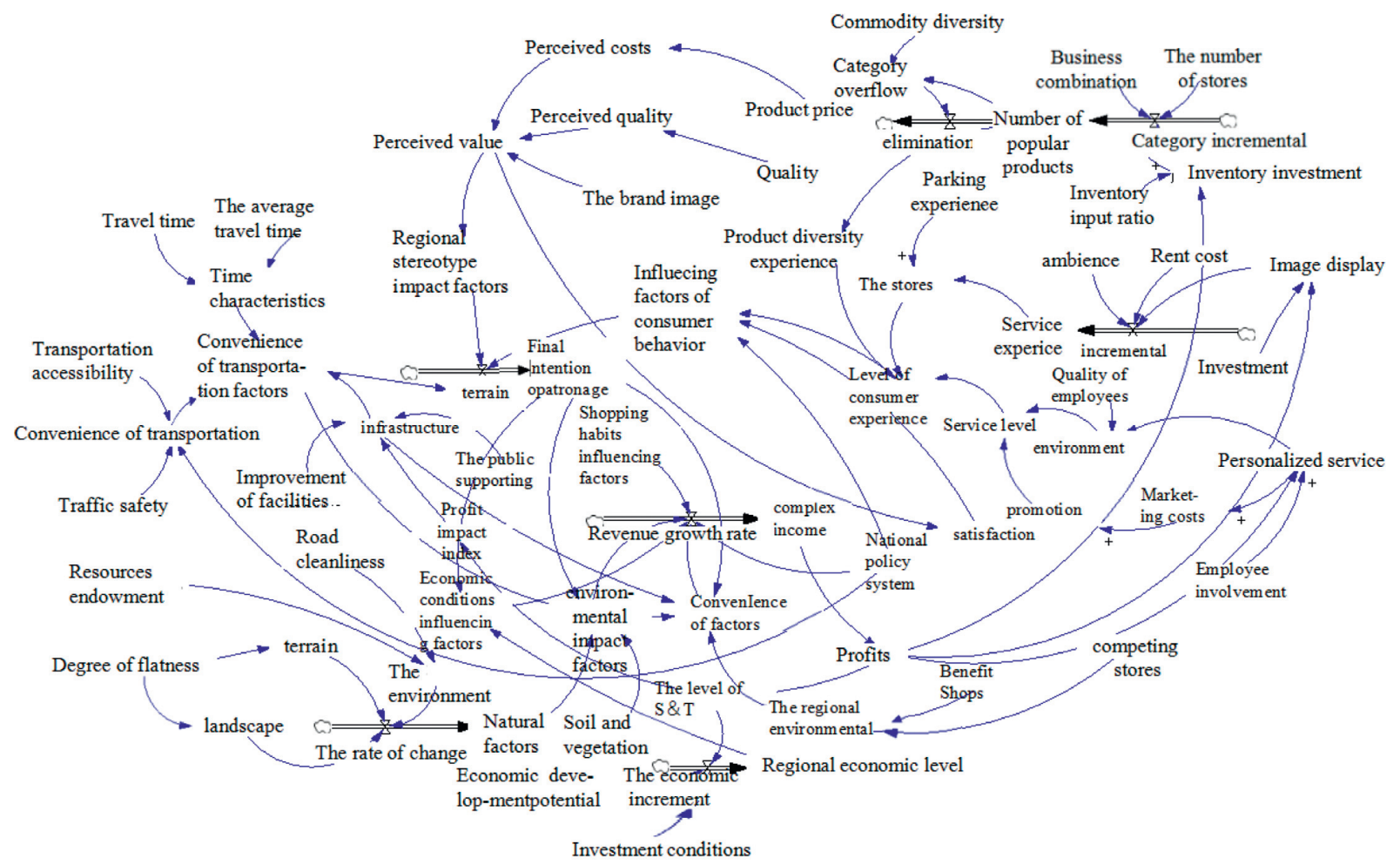

FIgURE 2: Flow stock map for the location of commercial complexes.

and the increase is small. The later increase in income was added. Although the increase was relatively significant, there was room for improvement.
4.2. Comparative Analysis on Site Selection Optimization of Commercial Complex. By adjusting the influence factors of regional stereotypes, consumer behavior patterns, traffic 
Final Patronage Willingness

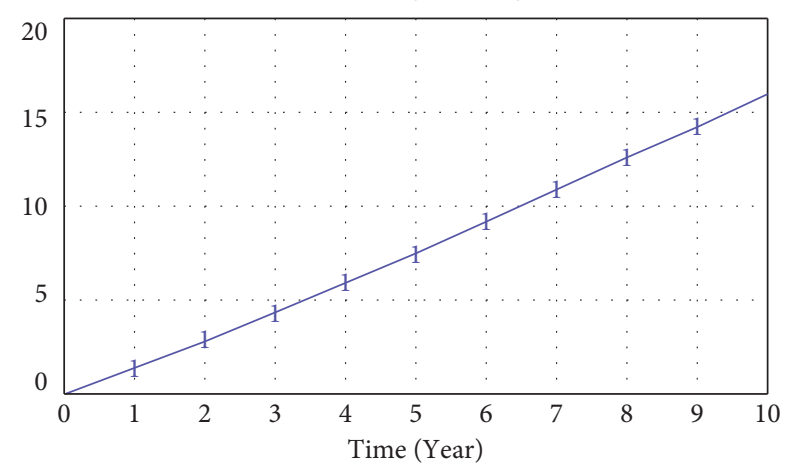

Final Patronage

$\begin{array}{lllllllllllll}\text { Willingness } & \text { :current } & 1 & 1 & 1 & 1 & 1 & 1 & 1 & 1 & 1 & 1 & 1\end{array}$

FIgURE 3: Simulation diagram of final patronage willingness.

Total Revenue of Commercial Complex

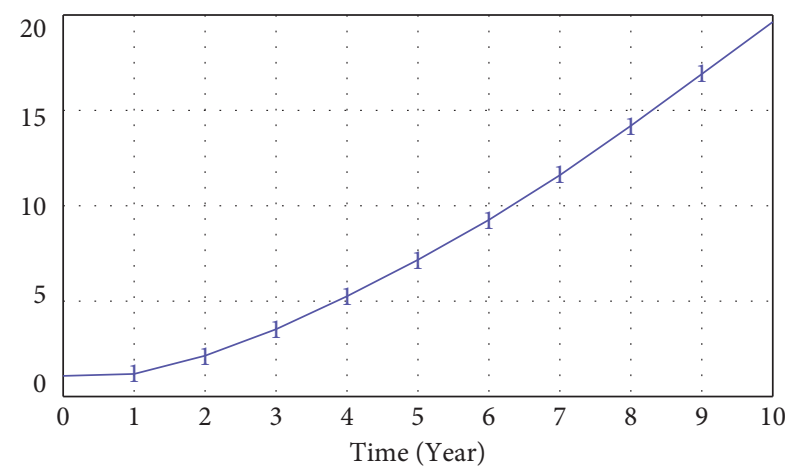

Total Revenue

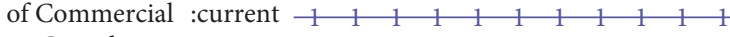
Complex

Figure 4: Simulation diagram of total revenue of commercial complex.

conditions, natural environment, regional economy, and operation level in the dynamic model of the system, the changes of consumers' preferences and the profits of commercial complexes were observed (see Figures 5-16).

Based on the previously mentioned comparison, this paper gives the following suggestions on the commercial complex location decision-making from six aspects of influencing factors of consumer's preference.

Regional Stereotypes. Before planning the business district or commercial complex project, the government planning department should fully understand the regional stereotypes of the area where the plot is located as far as possible to avoid planning the commercial complex land in the more negative imprint areas. If the land use planning is indeed restricted by some conditions that cannot be changed artificially, the planning department should take into consideration the planning conditions, such as volume rate AND construction withdrawal, and provide hardware support for the later change of these negative seals by the development enterprise.

Consumer Behavior. Before bidding for land, real estate development enterprises should conduct sufficient investigation and demonstration on the relevant information of the target consumers in the region. Project positioning shall be based on the regional consumption level and consumption capacity, and the project positioning shall not be too advanced or significantly higher than the regional consumption level and consumption capacity. At the same time, it is necessary to complement each functional section and pay attention to controlling the volume of commercial.

Transportation Convenience. Real estate development enterprises must fully understand the mid- and long-term planning of the public transport. The project should be actively integrated into the function of the city when it is located in the decision-making stage. During the construction design stage, the project should be connected with the site of the active and public transport on the building form, function, and dynamic line. Through the design method, the project of commercial complex becomes a kit of the city; for example, the entrance and exit of the subway directly connected to the interior of the commercial complex and the bus station setup near the entrance and exit of the commercial complex.

Regional Natural Conditions. The real estate development enterprises shall carry out the commercial theme positioning and function positioning according to the regional climate characteristics and landscape resource conditions, combine the theme and function with the surrounding historical culture and natural landscape as far as possible, and provide consumers with different consumption experiences, thus avoiding the dilemma of being in the same competition with other comprehensive projects.

Regional Economic Conditions. Real estate development enterprises should fully understand the total amount of regional economy, per capita disposable income and other basic information, and at the same time, they should also understand the regional future development planning, including the industrial layout, government fiscal and taxation policies, infrastructure construction, and so on.

Operational Level. Commercial complex projects are usually managed and operated by professional operating companies after the construction of real estate developers is completed. In reality, many projects in the operation team take over only to find that there is a big problem in the volume, function and dynamic line, which brings a lot of inconvenience to the late operation, so the operation team in the location decision-making stage should intervene, dividing business format and planning the internal business dynamic line according to the project positioning. In the construction stage, the operation team should put action to attract business, including the main stores, the secondary main stores, the various brands, and the merchants. 


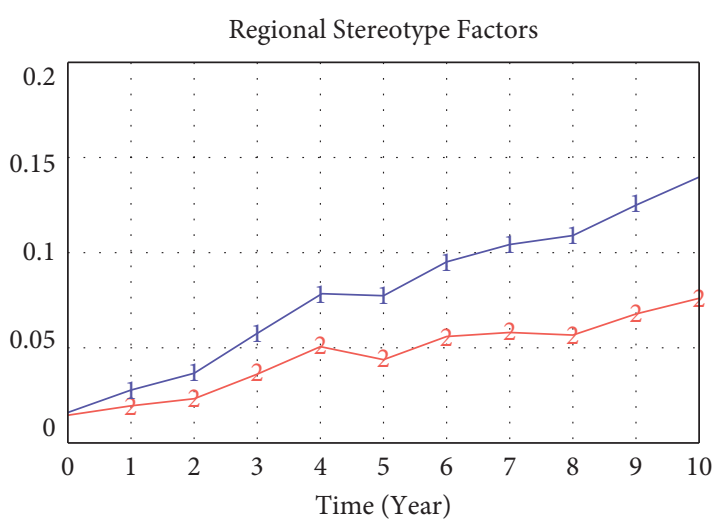

$\begin{array}{cllllllllll}\text { Regional } & \text { :after } & 1 & 1 & 1 & 1 & 1 & 1 & 1 & 1 & 1 \\ \text { Stereotype } & \text { :current } & 2 & 2 & 2 & 2 & 2 & 2 & 2 & 2 & 2\end{array}$

FiguRE 5: Comparison of regional stereotype optimization.

Final Patronage Willingness

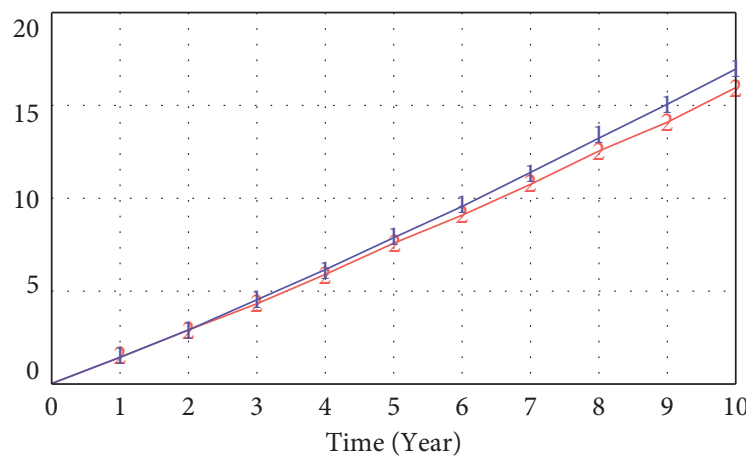

$\begin{array}{cllllllllll}\text { Final } & \text { :after } & 1 & 1 & 1 & 1 & 1 & 1 & 1 & 1 & 1 \\ \text { Patronage } & \text { :current } & 2 & 2 & 2 & 2 & 2 & 2 & 2 & 2 & 2 \\ \text { Willingness } & & & & & & & & & & \end{array}$

FIgURE 6: Comparison of optimization of patronage growth.

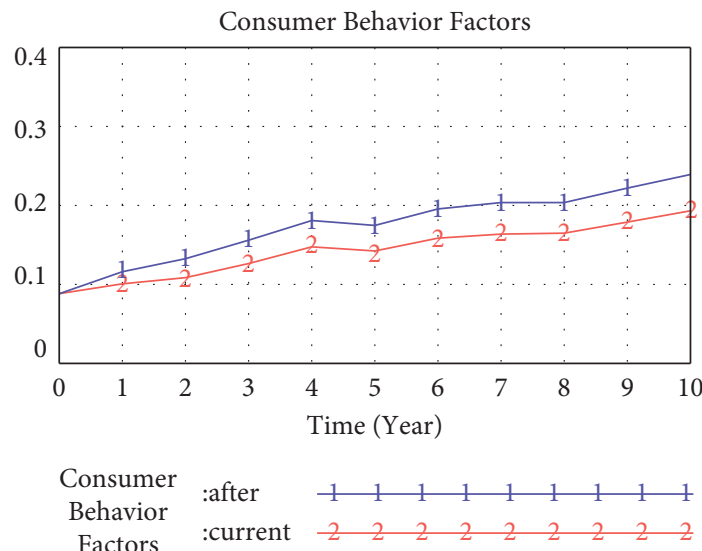

Figure 7: Comparison of consumer behavior factors after optimization.

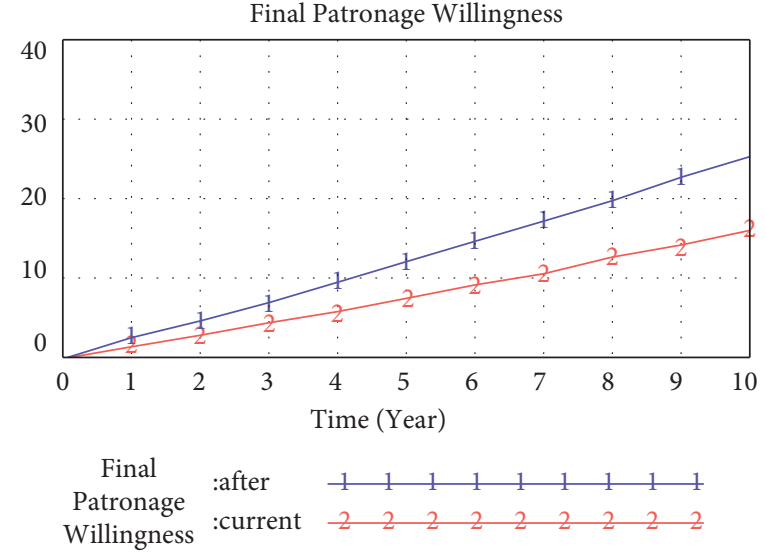

FIgURE 8: Comparison chart of optimization of growth rate of patronage willingness.

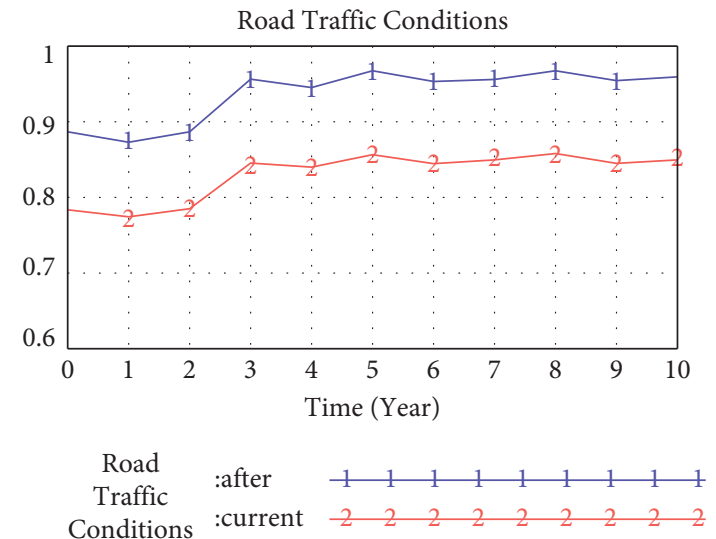

FIGURE 9: Optimization and comparison of factors affecting traffic convenience.

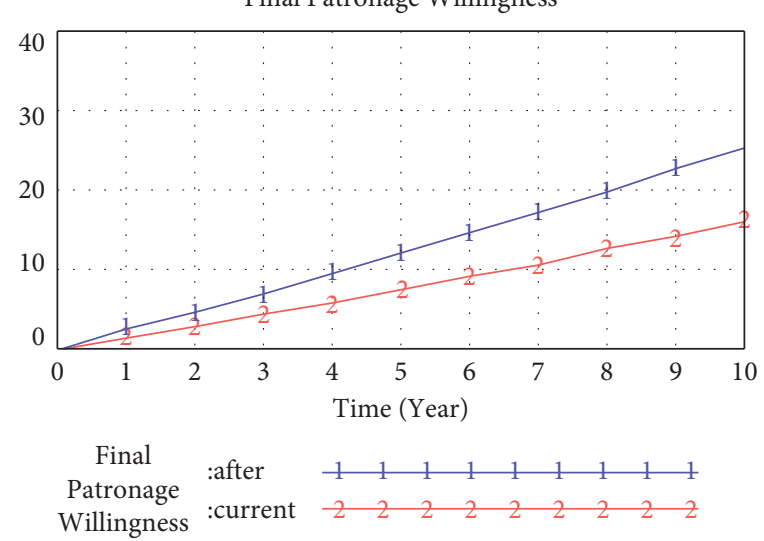

Figure 10: Comparison of final patron intention optimization. 
Natural Factors

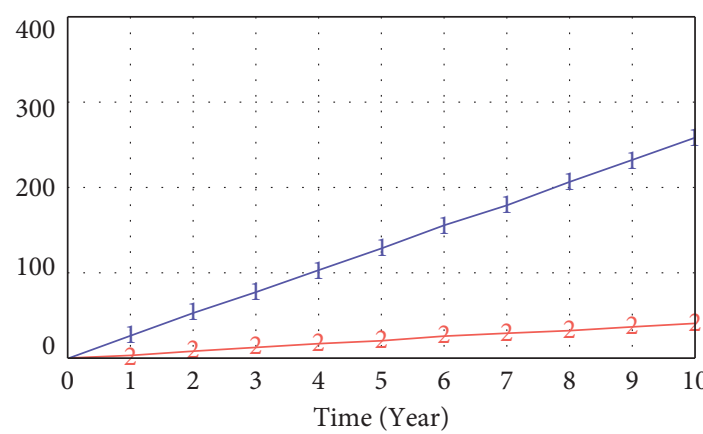

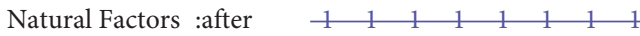

Natural Factors : current $\begin{array}{lllllllll}2 & 2 & 2 & 2 & 2 & 2 & 2 & 2\end{array}$

Figure 11: Comparison of natural factors optimization.

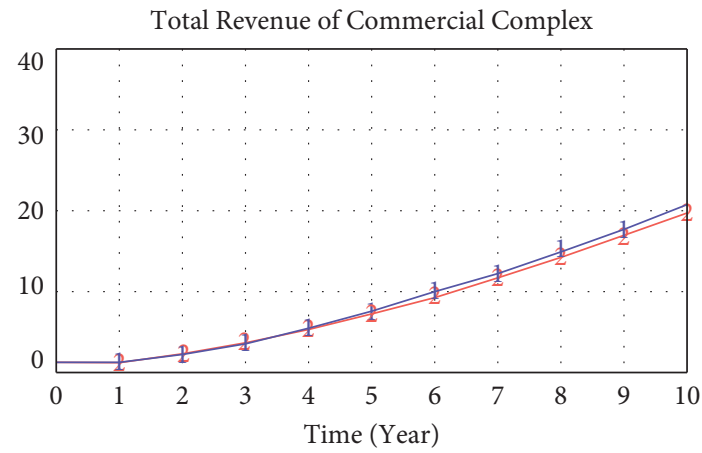

$\begin{array}{clllllllll}\begin{array}{c}\text { Total Revenue } \\ \text { of Commercial }\end{array} & \text { :after } & 1 & 1 & 1 & 1 & 1 & 1 & 1 & 1 \\ \text { Complex } & \text { :current } & 2 & 2 & 2 & 2 & 2 & 2 & 2 & 2\end{array}$

Figure 12: Comparison of comprehensive commercial income.

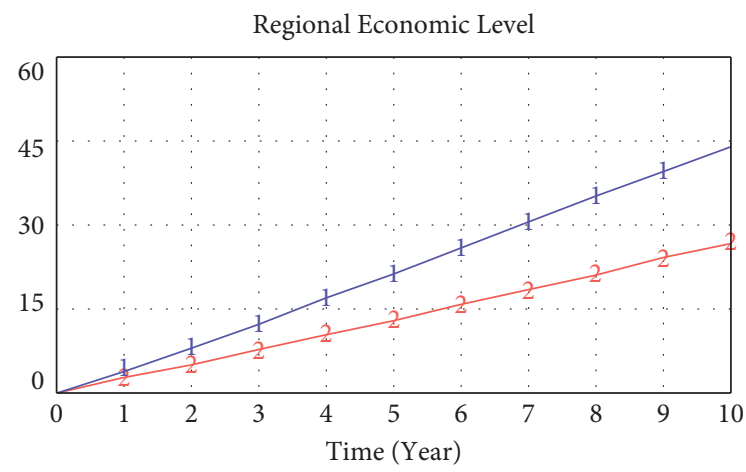

$\begin{array}{cllllllllll}\text { Regional } & \text { :after } & 1 & 1 & 1 & 1 & 1 & 1 & 1 & 1 & 1 \\ \begin{array}{c}\text { Economic } \\ \text { Level }\end{array} & \text { :current } & 2 & 2 & 2 & 2 & 2 & 2 & 2 & 2 & 2\end{array}$

FIgURE 13: Comparison of regional economic level optimization.

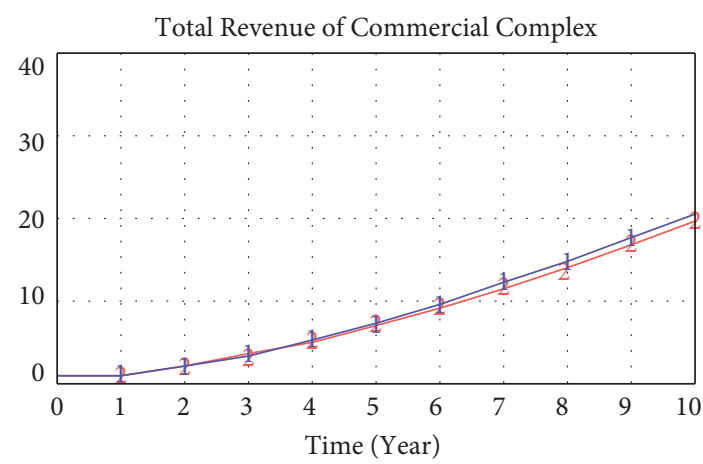

$\begin{array}{clllllllll}\begin{array}{c}\text { Total Revenue } \\ \text { of Commercial }\end{array} & \text { :after } & 1 & 1 & 1 & 1 & 1 & 1 & 1 & 1 \\ \text { Complex } & \text { :current } & 2 & 2 & 2 & 2 & 2 & 2 & 2 & 2\end{array}$

Figure 14: Comparison of total revenue optimization of commercial complexes.

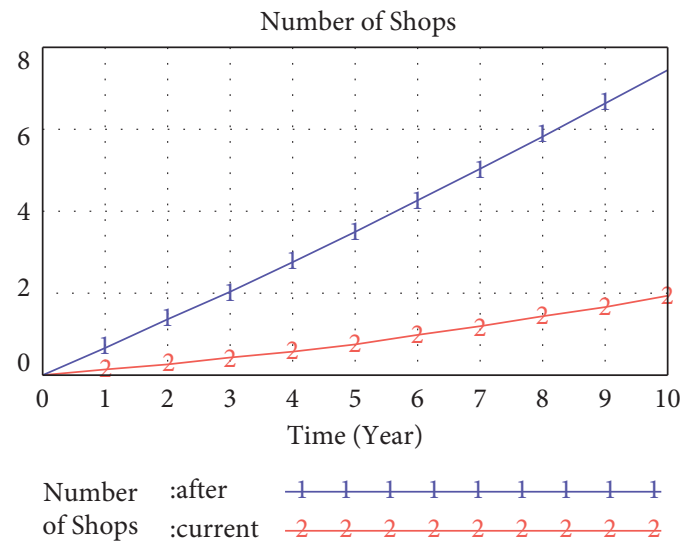

FIGURE 15: Comparison of optimization of the number of shops.

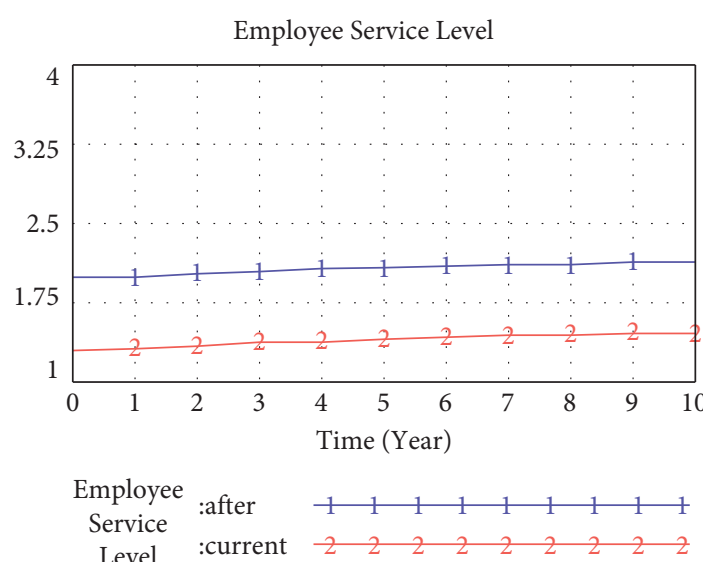

FIgURE 16: Comparison of employee service level optimization. 


\section{Conclusion}

This paper studies the influencing factors of consumers' preference and the influencing mechanism of various factors on the decision-making of commercial complex location and establishes the decision-making model of commercial complex location based on consumers' preference. Through the questionnaire data combined with statistical software, the model of this paper is tested. The empirical test provides the scientific basis for the decision-making of commercial complex location through the simulation and optimization analysis of commercial complex location.

This study has the following innovations. First, this paper introduced the customer's patronage intention, which has a decisive influence on the later operating income, to further optimize the site selection decision model. This paper fully considered the possibility of diversified selection of subjects caused by the development of the times, respecting the validity of the traditional commercial complex site selection decision model based on objective factors. Second, based on the theory of consumer planned behavior and the theory of customer perceived value, the paper analyzes the influencing factors of consumers' patronage intention to commercial complex, which enriches the research of patronage intention to the location decision of commercial complex. Third, the site selection decision-making index system of commercial complex based on consumer patronage intention is constructed to expand the research scope of site selection of commercial complex. Fourth, the system dynamics model of the commercial complex site selection decision is constructed, and the dynamic simulation of the commercial complex site selection decision is carried out, which enhances the explanatory ability of the influence of patronage intention on the commercial complex site selection decision. All these efforts make the decision result more in line with the actual demand to improve the rationality of site selection.

\section{Data Availability}

The datasets used and/or analyzed during the current study are available from the corresponding author on reasonable request.

\section{Conflicts of Interest}

The authors declare no potential conflicts of interest with respect to the research, authorship, and/or publication of this article.

\section{References}

[1] H. Hotelling, "Stability in competition," The Collected Economics Articles of Harold Hotelling, Springer, New York, NY, USA, pp. 50-63, 1990.

[2] G. Faltings, "The proof of Fermat's last theorem by R. Taylor and A. Wiles," Notices of the American Mathematical Society, vol. 42, no. 7, pp. 743-746, 1995.
[3] S. L. Hakimi, "Optimum locations of switching centers and the absolute centers and medians of a graph," Operations Research, vol. 12, no. 3, pp. 450-459, 1964.

[4] R. Hassin, A. Levin, and D. Morad, "Lexicographic local search and the p-center problem," European Journal of Operational Research, vol. 151, no. 2, pp. 265-279, 2003.

[5] R. C. Rosen, J. Catania, and L. Pollack, "Male sexual health questionnaire (MSHQ): scale development and psychometric validation," Urology, vol. 64, no. 4, pp. 777-782, 2004.

[6] M. A. Qian-Li and T. L. Huang, "Analysis of and study on the difficulties in the fire protection design of large commercial complex," Procedia Engineering, vol. 11, pp. 302-307, 2011.

[7] X. U. Jie and L. Jun, "ROPPONGI HILLS:urban Re-development commercial complex," Time + Architecture, vol. 2, 2005.

[8] R. G. Dugan, J. J. Clarkson, and J. T. Beck, "When causemarketing backfires: differential effects of one-for-one promotions on hedonic and utilitarian products," Journal of Consumer Psychology, vol. 31, pp. 1-19, 2021.

[9] K. P. Koller and A. Pennington-Cross, "The density of convenience retail and the type of traffic-commuting, local and retail," Journal of Real Estate Research, vol. 41, no. 2, pp. 319-346, 2019.

[10] Z. Liang, "Relationship between commercial complexes and urban space," Journal of Hefei University of Technology, vol. 29, no. 9, pp. 1166-1168, 2006.

[11] T. Hall and H. Barrett, Urban Geography, Routledge, Oxfordshire, UK, 2018.

[12] C. C. Williams, "The contribution of regional shopping centres to local economic development: threat or opportunity?" Area, vol. 24, pp. 283-288, 1992.

[13] S. Prashar, C. Parsad, and T. S. Vijay, "Segmenting young Indian impulsive shoppers," Journal of International Consumer Marketing, vol. 29, no. 1, pp. 35-47, 2017.

[14] J. W. Forrester, "Industrial dynamics:A majior breakthrough for decision makers," Harvard Business Review, vol. 36, no. 4, pp. 368-385, 1958.

[15] J. W. Forrester, "Urban dynamics," IMR; Industrial Management Review (pre-1986), vol. 11, no. 3, p. 67, 1970

[16] A. Raymond, A. James, E. Jacob, and J. Lyons, "Influence of perceptions and stereotypes of the nursing role on career choice in secondary students: a regional perspective," Nurse Education Today, vol. 62, pp. 150-157, 2018.

[17] M. Hřebíčková, S. Graf, T. Tegdes, and I. Brezina, "We are the opposite of you! Mirroring of national, regional and ethnic stereotypes," The Journal of Social Psychology, vol. 157, no. 6, pp. 703-719, 2017.

[18] Y. Wu and D. Ding, "An analysis on the factors affecting the activation and applications of stereotype in interpersonal cognition," Science of Social Psychology, no. 1, pp. 101-105, 2007.

[19] Yu Tian, "Analysis of Chinese consumer purchasing behavior pattern and marketing countermeasure," Enterprise Economy, no. 3, pp. 67-70, 2007.

[20] H. Xiao, J. Zhou, and Z. Liu, "On the change of consumption idea and its effect," Consumer Economics, no. 2, pp. 50-52, 1986.

[21] R. F. Gordon, M. O. C. Jorge, and B. P. Rafael, "Consumer behavior analysis and the marketing firm: measures of performance," Journal of Organizational Behavior Management, vol. 41, pp. 1-27, 2021.

[22] L. Xuxun, J. Zhicai, and N. Anning, "Review of reliability of urban network transportation system," Application Research of Computers, vol. 29, no. 8, pp. 2817-2820, 2012. 
[23] J. A. Ortega-García, F. A. López-Hernández, M. L. A. Funes, M. F. Sánchez Sauco, and R. Ramis, "My partner and my neighbourhood: the built environment and social networks' impact on alcohol consumption during early pregnancy," Health \& Place, no. 61, Article ID 102239, 2020.

[24] Z. Chen, "Study on the relationship between store image customer satisfaction and customer patronage intention," Review of Economy and Management, vol. 30, no. 6, pp. 76-81, 2014.

[25] G. Zhuang, M. Zhu, and Z. Liu, "The reason, intention, and action of customers' direction complaint: an empirical study based on the experiences of customers dissatisfied to electronic applause in China," Chinese Retail Research, vol. 1, no. 1, pp. 1-19, 2009. 